\title{
Electron and ion density variations before strong earthquakes $(M>6.0)$ using DEMETER and GPS data
}

\author{
M. Akhoondzadeh ${ }^{1,2}$, M. Parrot ${ }^{2}$, and M. R. Saradjian ${ }^{1}$ \\ ${ }^{1}$ Remote Sensing Division, Surveying and Geomatics Engineering Department, School of Engineering, \\ University of Tehran, Tehran, Iran \\ ${ }^{2}$ Laboratoire de Physique et Chimie de l'Environnement et de l'Espace (LPC2E)/CNRS, UMR6115, Orléans, France
}

Received: 28 October 2009 - Revised: 9 December 2009 - Accepted: 14 December 2009 - Published: 11 January 2010

\begin{abstract}
Using IAP (plasma analyzer) and ISL (Langmuir probe) experiments onboard DEMETER (Detection of Electromagnetic Emissions Transmitted from Earthquake Regions) satellite and GPS (Global Positioning System) measurements, we have statistically analyzed the variations of the electron and ion densities to search for disturbances in the vicinity of four large earthquakes prior to events. The indices $D_{\mathrm{st}}$ and $K_{\mathrm{p}}$ were used to distinguish pre-earthquake anomalies from the other anomalies related to the geomagnetic activities. For each studied case, a very good agreement was found between the different parameters estimated by DEMETER and GPS data in the detection of pre-seismic anomalies. Our statistics results show that the anomalous deviations prior to earthquakes have different sign from case to case, and that their amplitude depends on the magnitude of the earthquake. It has also been found that the electron density measured by the ISL experiment at night detects anomalous variations significantly before the earthquakes. The appearance of positive and negative anomalies in both of DEMETER and TEC (Total Electron Content) data during 1 to 5 days before all studied earthquakes during quiet geomagnetic conditions indicates that these anomalous behaviors are highly regarded as seismo-ionospheric precursors.
\end{abstract}

\section{Introduction}

Scientists acknowledge that a seismic electromagnetic anomaly is a climax of some process which begins a few days before the main event and stay until a few days after it. But, earthquakes as geophysical phenomena involve processes which are irregular, non-linear and complicated. These events are so sophisticated that the dynamic relations between their parameters result in high uncertainties in their

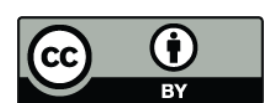

Correspondence to: $\mathrm{M}$. Akhoondzadeh (makhonz@ut.ac.ir) prediction. Therefore, it is necessary to find more reliable methods to closely study the process and its relevant parameters. During earthquake preparation, a dynamic process involves an energy transfer due to crust displacement and, at the time of the shock a break down between the source and the environment occurs. This change prior to the earthquake or along with it, may have different physical and chemical effects on the lithosphere, atmosphere and ionosphere, and accordingly makes it possible to be detected. These variations of lithosphere, atmosphere and ionosphere parameters before the main earthquakes are considered as hint of impending earthquakes (earthquake precursors).

Widespread researches on earthquake prediction over the last decades have resulted in the recognition of many earthquake precursors in the lithosphere, atmosphere and ionosphere. The effects of the pre-seismic activity on the ionosphere can be investigated using the ionospheric electron and ion densities. Perturbations of the ionospheric plasma without significant solar and geomagnetic disturbances may be attributed to earthquakes. These anomalies usually happen in the E-layer and F-layer and may be observed 1-10 days prior to the earthquake and continue a few days after it (see references below). It is difficult to extract the variations connected with the earthquakes particularly for the equatorial and low latitudinal ionosphere, which is highly dynamic and unpredictable (Sharma et al., 2008). Daily variations of the ionosphere depend on solar and geomagnetic activities, season, latitude and longitude and other unknown parameters. In the minimum solar cycle in the north hemisphere during noontime the maximum and minimum of the annual variations of the electron concentration are observed around the equinoxes and in the summer, respectively (Pulinets et al., 2003). Equatorial anomaly is seen as two peaks of electron density on each side of the Equator when, near the geomagnetic equator, the vertical movement which results from an imposed eastward electric field, is upward during the day. Its combination with preferential diffusion along the direction

Published by Copernicus Publications on behalf of the European Geosciences Union. 
of the geomagnetic field produces this equatorial anomaly. According to satellite measurements the equatorial anomaly also appears during nighttime in high solar activity conditions (Pulinets et al., 2003).

Recently various ground-based and satellite observations have shown the possibility of ionospheric disturbances generation by earthquake preparation processes. There is a lack of extensive ground experiments to monitor geophysical and geochemical parameters in most areas. But satellite experiments due to the vast coverage of the seismic zones of the Earth along with other sources of information are regarded as suitable means for earthquake study. They allow performing meaningful statistical studies with a much larger number of recorded events. Many papers and special monographs have been published on satellite observation of electromagnetic and ionospheric perturbations associated with seismic activity (Hayakawa and Molchanov, 2002; Pulinets and Boyarchuk, 2004). Russian scientists suggested the possibility of observing seismo-electromagnetic by satellites in the 1980s. In the past, data recorded by many different satellites (Alouette, GEOS 1 and 2, Cosmos 1809, OGO 6, Aureol 3, IK Bulgaria 1300, IK 19 and 24, AE-C, ISIS 2, TopexPoseidon, DE 2, DEMETER, GPS Satellites, Mir, etc.) have been used for understanding of the pre-seismic ionospheric variations. Gokhberg et al. (1983) studied on local plasma density and temperature variations measured onboard AE$\mathrm{C}$ and ISIS-2 satellites. Depuev and Zelenova (1996) observed that during a pre-earthquake period while the subpeak electron content remains almost unchanged, foF 2 is increased and $\mathrm{hmF} 2$ decreased at night. In another study, $\mathrm{Pu}-$ linets et al. (2003) used data of ground-based ionosondes and topside sounding from onboard Alouette- 2 and Intercosmos19 satellites together with local plasma measurements onboard the AE-C satellite to classify the main features of ionospheric variations associated with pre-seismic activity. Their work was based on hundreds of cases processed and also based on the knowledge of the ionospheric behavior under both quiet and geomagnetically disturbed conditions as a background for seismo-ionospheric variability separation. Parrot et al. (2006) and Sarkar et al. (2007) described examples of variation of plasma parameters recorded by DEMETER data over epicenters of some earthquakes before their occurrence. GPS (Global Positioning System) TEC (Total Electron Content) measurements have also made a considerable contribution to the understanding of seismoionospheric variations. Liu et al. (2004) statistically described the temporal parameters of the seismo-ionospheric precursors detected during 1-5 days prior to the earthquakes using TEC data for 20 major earthquakes in Taiwan. Devi et al. (2008) showed that electric field generated during earthquake preparatory processes has a strong effect in shaping the TEC profiles of the northern crest of the equatorial anomaly. Zhao et al. (2008) observed the anomalous enhancement of the seismo-ionospheric electron content 3 days prior to 12 May Sichuan earthquake using TEC variations.
In contrast with methods that assume the Earth's crust has an ideal homogeneous structure and disregard the physical and chemical changes occurring inside the earth, there exist hypothesis to explain the seismic electromagnetic mechanism based on geophysical and geochemical processes:

- direct wave production in a wide band spectrum by compression of rocks close to earthquake epicenter could be likely related to piezo-electric and triboelectric effects;

- rising fluids under the ground would lead to the emanation of warm gases;

- activation of positive holes that can reach the ground surface;

- emissions of radioactive gas or metallic ions such as radon which increase the Earth surface potential.

Pre-seismic electric field and its polarity cause the electrons in the F-layer to penetrate to lower layers and therefore to create anomaly in the ionospheric parameters. The thin layer of particles created before earthquakes due to ions radiation from the earth has a main role in transferring electric field to above atmosphere and then to the ionosphere. The penetration of this electric field to the ionosphere was first analytically calculated in Park and Dejnakarintra (1973) and then applied to the seismo-electromagnetic process by Kim et al. (1994) and Pulinets et al. (2000). The vertical electric field on the ground surface is transformed into an electric field perpendicular to the geomagnetic field lines. This zonal component leads to plasma density anomalies, which are observed in the earthquake area (Parrot, 1995; Tronin et al., 2002; Hayakawa and Molchanov, 2002; Pulinets et al., 2003; Namgaladze et al., 2009). In vicinity of the equatorial anomaly, a zonal component can be generated using the mechanism proposed in Pulinets (2009).

In spite of several reports published before launch of DEMETER satellite, the database collected was not accessible and sufficient to be used as ionospheric earthquake precursors. Only single parameter measurements like the changes in electron density, electric field or ion density prior to earthquakes have been taken into account. The electron density measurements need to be accompanied with temperature and ion composition measurements to reveal the nature of seismo-ionospheric variations. Therefore, it is necessary to carry out regular satellite observations in the ionosphere with highly sensitive measurements over seismically active and quiet regions. This will lead to creating an appropriate database for statistical study of the seismo-ionospheric effects. In this regard, the French micro-satellite DEMETER was launched on 29 June 2004. Moreover, GPS satellites with high time resolution measurements can be included as a supplementary way to study ionospheric variations over the regions supported by GPS ground stations. 
If it can be shown that ionospheric perturbations are real and systematic then they could be considered as short-term precursors, occurring between a few hours and a few days before the earthquakes. It should be noted that it is not expected that precursors can appear for any earthquake. Since not any individual precursor can be used as an accurate stand alone tool for the earthquake prediction, it is required to exploit and integrate different kinds of precursors from different experiments. In order to determine whether some of precursors have characteristics uniquely related to seismic activity, this study examines variations of electron density, ion density, electron temperature and total electron content measured by DEMETER and GPS satellites several days before and after some earthquakes. Section 2 will briefly explain the DEMETER experiments used in this study, the method of TEC calculation by GPS data and the geomagnetic data. The applied method for anomaly detection is shown in Sect. 3 . The seismo-ionospheric anomalies observed for four earthquakes are described in Sect. 4. Section 5 presents the striking findings observed by DEMETER and GPS data before events and Sect. 6 is for conclusions.

\section{Data}

\subsection{DEMETER satellite data}

The top part of ionosphere can be screened by some remote sensing satellites such as DEMETER. One of DEMETER scientific objectives is to detect anomalous variations of electromagnetic waves, particle fluxes and thermal plasma parameters which could be related to seismic activity. The orbit of DEMETER with an altitude of $710 \mathrm{~km}$ is polar, circular and nearly sun-synchronous and measurements are done at two different Local Time (LT): at 10:30 and 22:30. DEMETER experiments provide a nearly continuous survey of the plasma, waves and energetic particles. The electric field experiment ICE uses four electric probes to measure the three components of the electric field in a frequency range from DC up to $3.5 \mathrm{MHz}$; The search-coil magnetometer IMSC measures the three components of the magnetic field in a frequency range from a few $\mathrm{Hz}$ up to $20 \mathrm{kHz}$; The plasma analyzer IAP measures the ion density, composition, and temperature and flow velocity; The ISL, a set of two Langmuir probes, gives access to the electron density and temperature; and the solid state energetic particle detector IDP, measures the high energy electrons and protons. There are two modes of operation: (i) a survey mode to record low bit rate data all around the Earth at invariant latitudes less than $\sim 65^{\circ}$, and (ii) a burst mode to record high bit rate data above seismic regions.

In this study, data of IAP and ISL experiments in both survey and burst modes concerning each earthquake have been analyzed. ISL is designed to measure the electron density of plasma (in the range $10^{8}-5 \cdot 10^{11} \mathrm{~m}^{-3}$ ), electron temperature (in the range $600-10000^{\circ} \mathrm{K}$ ) and the potential of the satellite (in the range $\sim \pm 3 \mathrm{~V}$ ). Variations of these parameters are obtained with a time resolution of $1 \mathrm{~s}$ (Lebreton et al., 2006). The main aim of IAP experiment is to measure the main parameters of the thermal population that is the densities of the major ionospheric ions $\mathrm{H}^{+}, \mathrm{He}^{+}$and $\mathrm{O}^{+}$(in the range $10^{2}-5 \cdot 10^{5}$ ions $\mathrm{cm}^{-3}$ ), their temperature (range 500$\left.5000^{\circ} \mathrm{K}\right)$ and the ion flow velocity in the Earth's frame of reference (Berthelier et al., 2006).

Organized data and plots are available by half-orbits through a web server (http://DEMETER.cnrs-orleans.fr). In this study based on the time, geographic location and magnitude of each earthquake the closest satellite approaches from about 6 weeks before to 1 week after the earthquake were selected and IAP and ISL physical data concerning these orbits were analyzed.

\subsection{GPS satellite data}

Recently the extending network of GPS receivers has generated an increasing amount of data regarding the ionosphere state. TEC is the integrated number of the electrons within the block between the satellite and receiver or between two satellites. The GPS satellites transmit two frequencies of signals $\left(f_{1}=1575.42 \mathrm{MHz}\right.$ and $\left.f_{2}=1227.60 \mathrm{MHz}\right)$. The received signals in ground stations contain many effects such as ionosphere, troposphere, hardware and random errors. Ionosphere on the contrary of the troposphere is a dispersive medium and its effects can be evaluated with measurement of the modulations on the carrier phases recorded by dualfrequency receivers (Sardon et al., 1994). To study TEC variations, data of GIM (Global Ionospheric Map) provided by NASA Jet Propulsion Laboratory (JPL) were used. The GIM is constructed into $5^{\circ} \times 2.5^{\circ}$ (Longitude, Latitude) grid with a time resolution of $2 \mathrm{~h}$. GIM data are generated on a daily basis using data from about 150 GPS sites of the IGS (International Gnss Service) and other institutions. The Vertical Total Electron Content (VTEC) is modeled in a solar-geomagnetic reference frame using a spherical harmonics expansion up to degree and order of 15 . Instrumental biases, so-called differential P1-P2 code biases (DCB), for all GPS satellites and ground stations are estimated as constant values for each day (Mannucci et al., 1998). To convert line-of-sight TEC into vertical TEC, a modified single-layer model mapping function approximating the JPL extended block model mapping function is adopted (http://www.gsfc.nasa.gov/). In this research, TEC data based on the date and geographic location of each earthquake from about 6 weeks before to 1 week after the main event were processed.

\subsection{Geomagnetic data}

The ionospheric parameters are affected by solar geophysical conditions and geomagnetic storms especially in the equatorial and polar regions. Also, auroral activity has an important role in the mid-latitude ionosphere perturbations. In 
other words, the ionosphere current and equatorial stormtime ring current in periods of solar-terrestrial disturbances produce significant geomagnetic field disturbances observed on the ground. Accordingly, the measured parameters may display variations in absence of seismic activity. Therefore, it is difficult to separate pre-seismic ionospheric phenomena from the ionospheric disturbances due to the solar-terrestrial activities (Ondoh, 2008). Consequently, to discriminate the seismo-ionospheric perturbations from geomagnetic disturbances, the geomagnetic indices $D_{\mathrm{st}}$ and $K_{\mathrm{p}}$ (http://spider. ngdc.noaa.gov) were checked. The $K_{\mathrm{p}}$ index monitors the planetary activity on a worldwide scale while the $D_{\text {st }}$ index records the equatorial ring current variations (Mayaud, 1980). The ionospheric effect of a geomagnetic storm has a global impact being observed all over the world while, the seismogenic effect is observed only by stations with distance less than $2000 \mathrm{~km}$ from the potential epicenter (Pulinets et al., 2003). It should be noted that an ionospheric storm usually lasts $8-48 \mathrm{~h}$ while the seismoionospheric disturbances have duration of 3-4h, a few days before the earthquake (Pulinets et al., 2003; Pulinets and Boyarchuk, 2004; Gousheva et al., 2008).

\section{Applied method for anomaly detection}

In each case study, using reported geographic latitude and longitude concerning the earthquake epicenter, we have analyzed ionospheric parameters extracted from DEMETER and GPS satellites during about 45 days before to 10 days after the event over area depending on earthquake magnitude. The radius of this area can be estimated using the Dobrovolsky formula $R=10^{0.43 M}$ where $R$ is the radius of the earthquake preparation zone, and $M$ is the earthquake magnitude (Dobrovolsky et al., 1979). Furthermore, studies show that the irregularities in the electron concentration happen when the area on the ground surface occupied by the anomalous field exceeds $200 \mathrm{~km}$ in diameter. Also, previous studies show that the maximum of the affected area in the ionosphere does not coincide with the vertical projection of the epicenter of the impending earthquake and is shifted towards the Equator in high and middle latitudes (Pulinets et al., 2003). Therefore, it is preferable to process data recorded in satellite orbits close to epicenter during days before earthquakes. Accordingly, optimum value for distance between the satellite and the epicenter was selected in terms of DEMETER satellite altitude and earthquake zone radius. The same way was applied for analyzing TEC and data of GPS ground stations near to epicenter of earthquakes. In order to search for earthquake anomaly from ionosphere variations a reasonable range for ionosphere regular variations must be determined. Many semi empirical and empirical models (e.g. IRI-2000) have been developed for long- and short-term predictions of the ionospheric parameters (Bilitza, 2001). It means that discrepancy differences between predictions of these models and measured data can be regarded as anomaly before earth- quakes. But our experiments show that the results of these models are not in good agreement with measurements even during quiet conditions. This contradiction can be vindicated by the low sensitivity of these models to detect fast changes in ionosphere during solar and geomagnetic activity. Bolzan et al. (2009) used the wavelet transform to obtain the time variability of the main periodicities of intermittent phenomena during a geomagnetic storm to increase the efficiency of the models. It appears that there is a necessity for more detailed studies of intermittent and non intermittent phenomena in ionosphere that affect variations caused by a seismic electric field.

The median and the inter-quartile range of data are utilized to construct their upper and lower bound in order to separate seismic anomalies from the background of natural variations (Liu et al., 2004). In calculation of statistical parameters, the length of the period was selected as about 55 days in order to avoid affects by the seasonal variations. The upper and lower bound of the mentioned range can be calculated using the following equations:

$x_{\text {high }}=M+k \cdot \mathrm{IQR}$
$x_{\text {low }}=M-k \cdot \mathrm{IQR}$

$x_{\text {low }}<x<x_{\text {high }} \Rightarrow-k<\frac{x-M}{\mathrm{IQR}}<k ; D x=\frac{x-M}{\mathrm{IQR}}$

where $x, x_{\text {high }}, x_{\text {low }}, M$, IQR and $D x$ are the parameter value, upper bound, lower bound, median value, inter-quartile range and differential of $x$, respectively. According to this, if the absolute value of $D x$ would be greater than $k,(|D x|>k)$, the behavior of the relevant parameter $(x)$ is regarded as anomalous. According to Eq. (3), $p= \pm 100 \cdot(|D x|-k) / k$ indicates the percentage of parameter change from the undisturbed state. The $k$ value must be proportional to the earthquake magnitude. Namely, for large earthquakes with magnitude greater than 7.0, $k$ can be selected greater than 2.0. Variations of the ionosphere parameters depend on local time. Therefore, in calculation of TEC, M and IQR values were evaluated over the total time interval of interest for each period of $2 \mathrm{~h}$ in Local Time.

\section{Observations and case studies}

As mentioned in the introduction section, in order to clear up uncertainty to earthquake anomaly detection, our study is based on a few types of precursors, sensors and case studies. Seismo-ionospheric disturbances within a few days before earthquakes have been registered in $73 \%$ of earthquakes with magnitude 5.0 , and in $100 \%$ of earthquakes with magnitude 6.0 (Pulinets, 2003). Using visual inspection in seismic databases (http://earthquake.usgs.gov, http://www. emsc-csem.org, http://iiees.ac.ir, and http://geophysics.ut. ac.ir) and regarding the availability of DEMETER and 
Table 1. List of the earthquakes selected in this study (reported by http://earthquake.usgs.gov/).

\begin{tabular}{lrlllr}
\hline Area & Date & $\begin{array}{l}\text { Time } \\
(\mathrm{UTC})\end{array}$ & $\begin{array}{l}\text { Geographic latitude, } \\
\text { longitude }\end{array}$ & $\begin{array}{l}\text { Magnitude } \\
\left(M_{\mathrm{W}}\right)\end{array}$ & $\begin{array}{r}\text { Focal depth } \\
(\mathrm{km})\end{array}$ \\
\hline Samoa Islands & 29 Sept 2009 & $17: 48: 10.99$ & $15.49 \mathrm{~S}, 172.10 \mathrm{~W}$ & 8.1 & 18.0 \\
L'Aquila, Italy & 6 Apr 2009 & $01: 32: 39.00$ & $42.33 \mathrm{~N}, 13.33 \mathrm{E}$ & 6.3 & 8.0 \\
Sichuan, China & 12 May 2008 & $06: 28: 01.57$ & $31.00 \mathrm{~N}, 103.32 \mathrm{E}$ & 7.9 & 19.0 \\
Hormozgan, Iran & 28 Feb 2006 & $07: 31: 02.65$ & $28.12 \mathrm{~N}, 56.87 \mathrm{E}$ & 6.0 & 18.0 \\
\hline
\end{tabular}
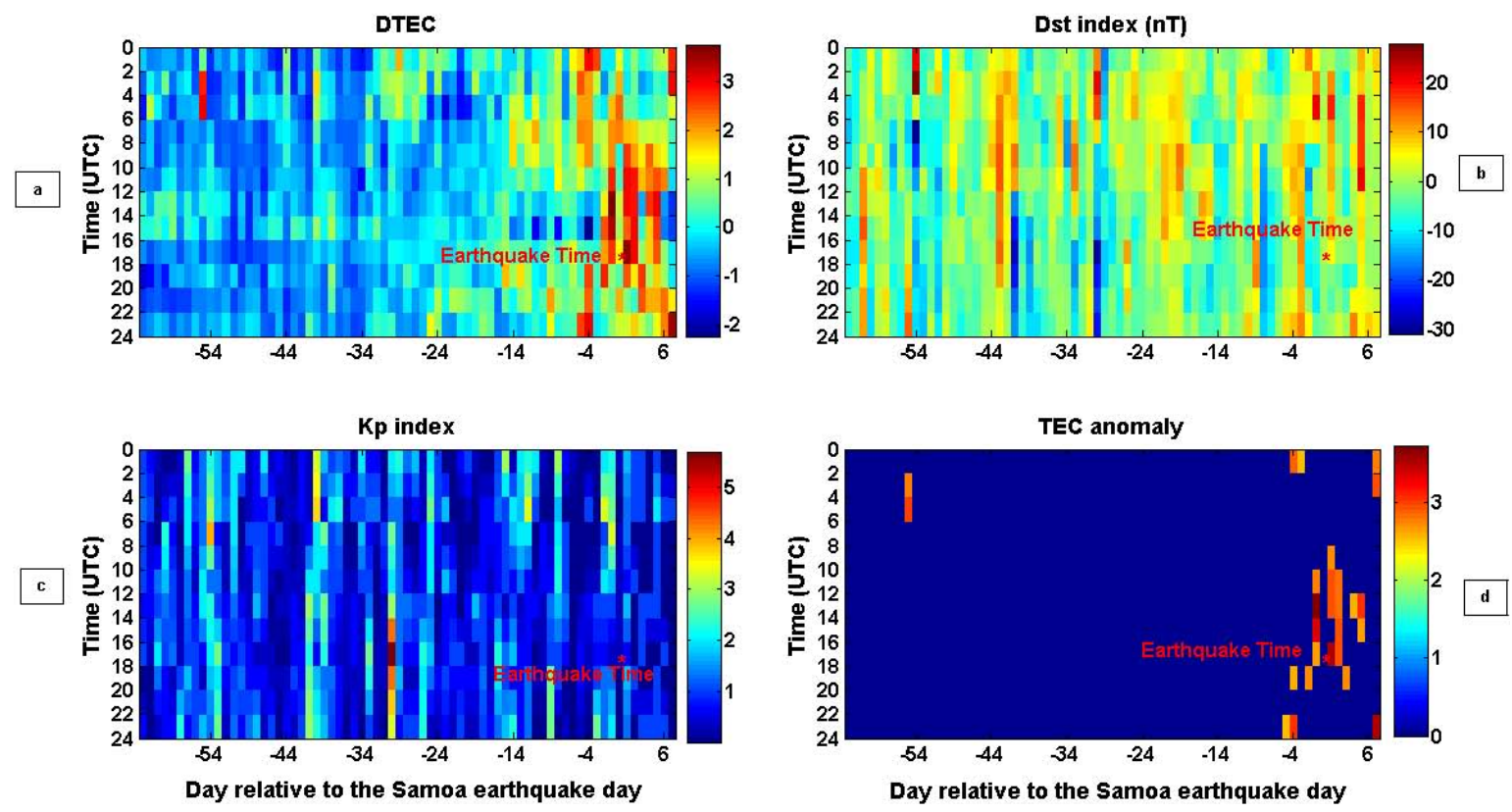

Fig. 1. Results of analysis for the Samoa earthquake (29 September 2009) from 28 July to 6 October 2009. The earthquake time is indicated by an asterisk. The $\mathrm{x}$-axis represents the day relative to the earthquake day. The y-axis represents the time UTC (LT=UTC-11:00). (a) DTEC variations. (b) Variations of $D_{\text {st }}$ geomagnetic index. (c) Variations of $K_{\mathrm{p}}$ geomagnetic index. (d) TEC anomaly detected based on: $|\mathrm{DTEC}|>2.5, K_{\mathrm{p}}<2.5$ and $D_{\mathrm{st}}>-20(\mathrm{nt})$.

GPS data, four earthquakes which happened in Samoa Islands, Sichuan (China), L'Aquila (Italy) and Hormozgan (Iran) have been incorporated in this analysis. Table 1 indicates some characteristics of these earthquakes.

\subsection{Samoa Islands earthquake}

In Samoa Islands, the largest earthquake so far, took place at 06:48:11 LT on 29 September 2009 with a magnitude $M_{\mathrm{W}}=8.1$ (see Table 1). Figure 1a illustrates the DTEC values estimated according to Eq. (3) from 28 July to 6 October 2009 using GPS ground stations close to the epicenter. By visual inspection of DTEC variations, perturbations can be seen near to the earthquake date. But to isolate earthquake perturbations from solar and magnetic disturbances, variations of $D_{\text {st }}$ and $K_{\mathrm{p}}$ indices during the same time interval were incorporated. Figure $1 \mathrm{~b}$ and c illustrates, respectively, the variations of $D_{\mathrm{st}}$ and $K_{\mathrm{p}}$ indices that were relatively quiet during days prior to the earthquake. The $K_{\mathrm{p}}$ index shows a sudden magnetic activity on 30 August 2009, 30 days before the earthquake from 04:00 to 14:00 LT.

After integration of these three information layers, the TEC anomaly was derived during quiet geomagnetic conditions. In other words, anomalous TEC is only depicted at times when $|\mathrm{DTEC}|>2.5, K_{\mathrm{p}}<2.5$ and $D_{\text {st }}>-20(\mathrm{nT})$. The TEC anomaly is represented as a function of the Universal Time Coordinate (UTC) and number of days relative to the main shock onset; an asterisk represents the time of the earthquake (Fig. 1d). As shown in Fig. 1d, strong enhancement of TEC anomaly can be seen during several time intervals (Table 2). Anomalous TEC variations of the order of $+2 \%$ began on 24 September, 5 days prior to the earthquake. The TEC anomaly on 28 September, 1 day before event, was expanded and amplified with a maximum value reaching $+49 \%$ at 03:00 LT. This anomaly continues some days after the earthquake. Seismic reports related to this 
Table 2. List of the earthquakes and detected anomalies. Day is relative to the earthquake day. Value calculated by: $(x-M) / \mathrm{IQR}: x, M$ and IQR are parameter value, median of parameter values in defined period and inter-quartile range of parameter values in defined period, respectively. Values calculated in terms of the upper and lower bounds defined for each earthquake as follow: Samoa (DEMETER: $M \pm 1.8 \cdot \mathrm{IQR}$; TEC: $M \pm 2.5 \cdot \mathrm{IQR})$, Sichuan (DEMETER: $M \pm 1.5 \cdot \mathrm{IQR}$; TEC: $M \pm 2.5 \cdot \mathrm{IQR})$, L'Aquila (DEMETER: $M \pm 1.5 \cdot \mathrm{IQR}$; TEC: $M \pm 1.5 \cdot \mathrm{IQR})$ and Hormozgan (DEMETER: $M \pm 1.8 \cdot \mathrm{IQR}$; TEC: $M \pm 2 \cdot \mathrm{IQR}$ ).

\begin{tabular}{|c|c|c|c|c|c|c|c|c|c|c|}
\hline \multicolumn{3}{|c|}{ Earthquake } & \multicolumn{3}{|c|}{ TEC } & \multicolumn{5}{|c|}{ DEMETER (Level 1) } \\
\hline Name & Date & $\begin{array}{l}\text { Time } \\
\text { (LT) }\end{array}$ & Day & $\begin{array}{l}\text { Time } \\
\text { (LT) }\end{array}$ & Value & Day & Value & Sensor & Parameter & $\begin{array}{l}\text { Time } \\
\text { (LT) }\end{array}$ \\
\hline \multirow{17}{*}{$\begin{array}{l}\text { Samoa } \\
\text { Islands }\end{array}$} & \multirow[t]{17}{*}{29 Sep 2009} & \multirow[t]{17}{*}{ 06:48:10.99 } & 1 & 01:00 & +2.78 & 2 & +3.24 & ISL & Electron Temperature & $22: 30$ \\
\hline & & & 1 & 03:00 & +3.73 & 3 & +2.12 & IAP & $\mathrm{O}^{+}$Density & $22: 30$ \\
\hline & & & 1 & 05:00 & +3.38 & 3 & +2.08 & IAP & Total Ion Density & $22: 30$ \\
\hline & & & 1 & 07:00 & +2.63 & 3 & +2.28 & ISL & Electron Density & $22: 30$ \\
\hline & & & 2 & 09:00 & +2.73 & 4 & +3.0 & IAP & Total Ion Density & $10: 30$ \\
\hline & & & 2 & $15: 00$ & +2.54 & 4 & +3.18 & IAP & $\mathrm{O}^{+}$Density & $10: 30$ \\
\hline & & & 3 & $15: 00$ & +2.91 & 4 & -2.87 & IAP & Ion Temperature & $10: 30$ \\
\hline & & & 4 & 09:00 & +2.60 & 4 & +3.01 & ISL & Electron Density & $10: 30$ \\
\hline & & & 4 & $13: 00$ & +3.07 & 4 & -1.82 & ISL & Electron Temperature & $10: 30$ \\
\hline & & & 5 & 13:00 & +2.55 & 5 & +2.89 & ISL & Electron Density & $22: 30$ \\
\hline & & & & & & 6 & +1.96 & ISL & Electron Density & $22: 30$ \\
\hline & & & & & & 8 & +1.65 & IAP & Total Ion Density & $10: 30$ \\
\hline & & & & & & 8 & +2.24 & IAP & $\mathrm{O}^{+}$Density & $10: 30$ \\
\hline & & & & & & 8 & +2.07 & IAP & $\mathrm{O}^{+}$Density & $22: 30$ \\
\hline & & & & & & 8 & +2.04 & IAP & Total Ion Density & $22: 30$ \\
\hline & & & & & & 8 & +2.8 & ISL & Electron Density & $22: 30$ \\
\hline & & & & & & 11 & +2.07 & ISL & Electron Density & $22: 30$ \\
\hline \multirow{12}{*}{$\begin{array}{l}\text { L'Aquila, } \\
\text { Italy }\end{array}$} & \multirow[t]{12}{*}{6 Apr 2009} & \multirow[t]{12}{*}{ 03:32:39.00 } & 2 & $24: 00$ & +1.92 & 0 & +1.72 & IAP & Total Ion Density & $10: 30$ \\
\hline & & & 4 & $24: 00$ & +1.84 & 0 & +1.83 & IAP & Total Ion Density & $22: 30$ \\
\hline & & & & & & 1 & +2.58 & IAP & Total Ion Density & $22: 30$ \\
\hline & & & & & & 1 & +1.72 & IAP & Total Ion Density & $10: 30$ \\
\hline & & & & & & 1 & +2.21 & ISL & Electron Density & $10: 30$ \\
\hline & & & & & & 2 & +1.65 & ISL & Electron Density & $10: 30$ \\
\hline & & & & & & 2 & +2.64 & IAP & Total Ion Density & $22: 30$ \\
\hline & & & & & & 2 & +2.67 & ISL & Electron Density & $22: 30$ \\
\hline & & & & & & 3 & +3.35 & ISL & Electron Density & $22: 30$ \\
\hline & & & & & & 3 & +2.30 & IAP & Total Ion Density & $22: 30$ \\
\hline & & & & & & 8 & +1.93 & ISL & Electron Density & $10: 30$ \\
\hline & & & & & & 8 & +1.44 & IAP & Total Ion Density & $10: 30$ \\
\hline \multirow{15}{*}{$\begin{array}{l}\text { Sichuan, } \\
\text { China }\end{array}$} & \multirow[t]{15}{*}{12 May 2008} & \multirow[t]{15}{*}{$14: 28: 01.57$} & 1 & $12: 00$ & -2.59 & 0 & +1.6 & IAP & Ion Temperature & $10: 30$ \\
\hline & & & 2 & $12: 00$ & -03.10 & 2 & -2.18 & IAP & $\mathrm{O}^{+}$Density & $10: 30$ \\
\hline & & & 2 & $14: 00$ & -03.07 & 2 & -2.28 & IAP & Total Ion Density & $10: 30$ \\
\hline & & & 3 & $12: 00$ & -03.10 & 2 & -2.05 & ISL & Electron Density & $10: 30$ \\
\hline & & & 3 & $14: 00$ & -2.92 & 2 & +1.98 & ISL & Electron Temperature & $10: 30$ \\
\hline & & & 3 & $24: 00$ & -2.50 & 3 & +1.73 & ISL & Electron Temperature & $10: 30$ \\
\hline & & & 4 & 02:00 & -2.69 & 3 & -1.86 & ISL & Electron Density & $10: 30$ \\
\hline & & & 4 & 04:00 & -2.87 & 3 & -2.40 & IAP & $\mathrm{O}^{+}$Density & $10: 30$ \\
\hline & & & 4 & 06:00 & -2.69 & 3 & -2.26 & IAP & Total Ion Density & $10: 30$ \\
\hline & & & 10 & 06:00 & -2.55 & 3 & -1.70 & ISL & Electron Density & $22: 30$ \\
\hline & & & & & & 9 & +2.09 & ISL & Electron Density & $22: 30$ \\
\hline & & & & & & 10 & +2.37 & IAP & $\mathrm{O}^{+}$Density & $22: 30$ \\
\hline & & & & & & 10 & +2.13 & IAP & Total Ion Density & $22: 30$ \\
\hline & & & & & & 10 & -3.22 & ISL & Electron Temperature & $22: 30$ \\
\hline & & & & & & 11 & +2.5 & ISL & Electron Temperature & $22: 30$ \\
\hline \multirow{2}{*}{$\begin{array}{l}\text { Hormozgan, } \\
\text { Iran }\end{array}$} & \multirow[t]{2}{*}{28 Feb 2006} & \multirow[t]{2}{*}{ 11:01:02.65 } & 1 & 05:30 & +2.43 & 1 & +1.96 & ISL & Electron Density & $22: 30$ \\
\hline & & & & & & 2 & +2.45 & ISL & Electron Density & $22: 30$ \\
\hline
\end{tabular}



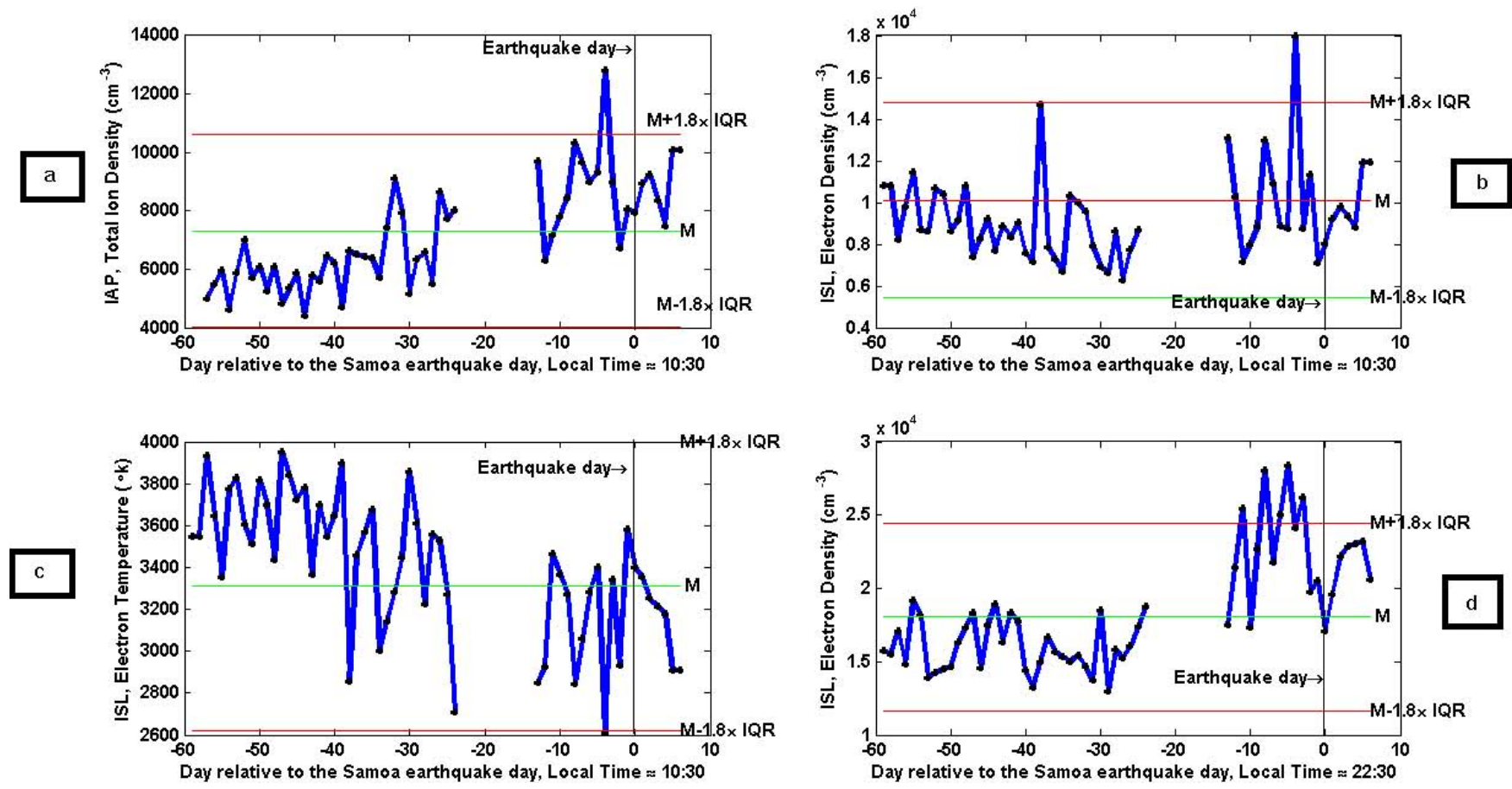

Fig. 2. Results of DEMETER data analysis for the Samoa earthquake (29 September 2009) from 1 August to 5 October 2009. Due to the operation of satellite in safe mode a time gap is observed from 7 to 15 September 2009. The earthquake day is represented as vertical dotted line. The green horizontal lines indicate the upper and lower bounds ( $M \pm 1.8 \cdot \mathrm{IQR})$. The blue horizontal line indicates the median value $(M)$. The $\mathrm{x}$-axis represents the day relative to the earthquake day. The y-axis represents (a) total ion density derived by the measurements of the IAP experiment during day, (b) electron density derived by the measurements of the ISL experiment during day, (c) electron temperature derived by the measurements of the ISL experiment during day, and (d) electron density derived by the measurements of the ISL experiment during night.

earthquake indicate several aftershocks registered with fairly high magnitudes. The largest aftershock $\left(M_{\mathrm{b}}=6.0\right)$ occurred at 12:45 LT, about $6.0 \mathrm{~h}$ after the earthquake.

In order to confirm observed TEC anomalies, DEMETER data were used. Figure 2 illustrates variations of different parameters extracted from DEMETER experiments data over Samoa earthquake region from 1 August to 5 October 2009. It concerns electron density $\left(\mathrm{cm}^{-3}\right)$ and electron temperature $(\mathrm{K})$ from ISL and total ion density $\left(\mathrm{cm}^{-3}\right)$ from IAP, which were recorded when satellite orbits have been close to the earthquake epicenter (i.e. less than $1500 \mathrm{~km}$ ). The vertical dotted line in each panel shows the earthquake date and the ordinate of each panel indicates day related to the earthquake day. Median and bounds (upper and lower) are seen as blue and green horizontal lines, respectively. Due to operation of satellite in safe mode a time gap is observed from 7 to 15 September 2009. In Fig. 2a, an increase in total ion density is clearly observed at $\sim 10: 30 \mathrm{LT}, 4$ days before the earthquake. Variations of total ion density clearly exceed the upper bound $(M+1.8 \cdot \mathrm{IQR})$ of the order of $67 \%$. Similar to this another unusual behavior is seen in electron density variations (Fig. 2b), when it reaches a maximum value, at $\sim 10: 30$ LT, 4 days before the earthquake and ex- ceeds the upper bound of the order of $67 \%$. Because of the inverse relation between electron density and electron temperature, observed anomaly in electron density can be acknowledged by the electron temperature variations. Figure $2 \mathrm{c}$ illustrates that electron temperature has reached to its minimum value $(D x=-1.82)$ at $\sim 10: 30 \mathrm{LT}, 4$ days before the earthquake. Irregularities of electron density also occurred at $\sim 22: 30 \mathrm{LT}, 11,8,5$ and 3 days before the earthquake that among them, the maximum irregularity intensity (i.e. $60.5 \%$ ) observed 5 days before the earthquake. Such anomalous variations were also observed in other measured parameters at night before earthquakes (see Table 2).

\subsection{Sichuan, China earthquake}

On 12 May 2008 at 14:28:01.57 LT a strong earthquake of magnitude $M_{\mathrm{W}}=7.9$ occurred in southwest China (see Table 1). Figure 3a displays the DTEC values during the period 1 April-22 May 2009, derived from GPS stations close to the epicenter. Figure $3 \mathrm{~b}$ and $\mathrm{c}$ illustrates that quiet geomagnetic conditions exist around the earthquake date. After fusion of DTEC, $D_{\text {st }}$ and $K_{\mathrm{p}}$ data, the TEC anomaly map was derived at the region. Figure $3 \mathrm{~d}$ clearly 

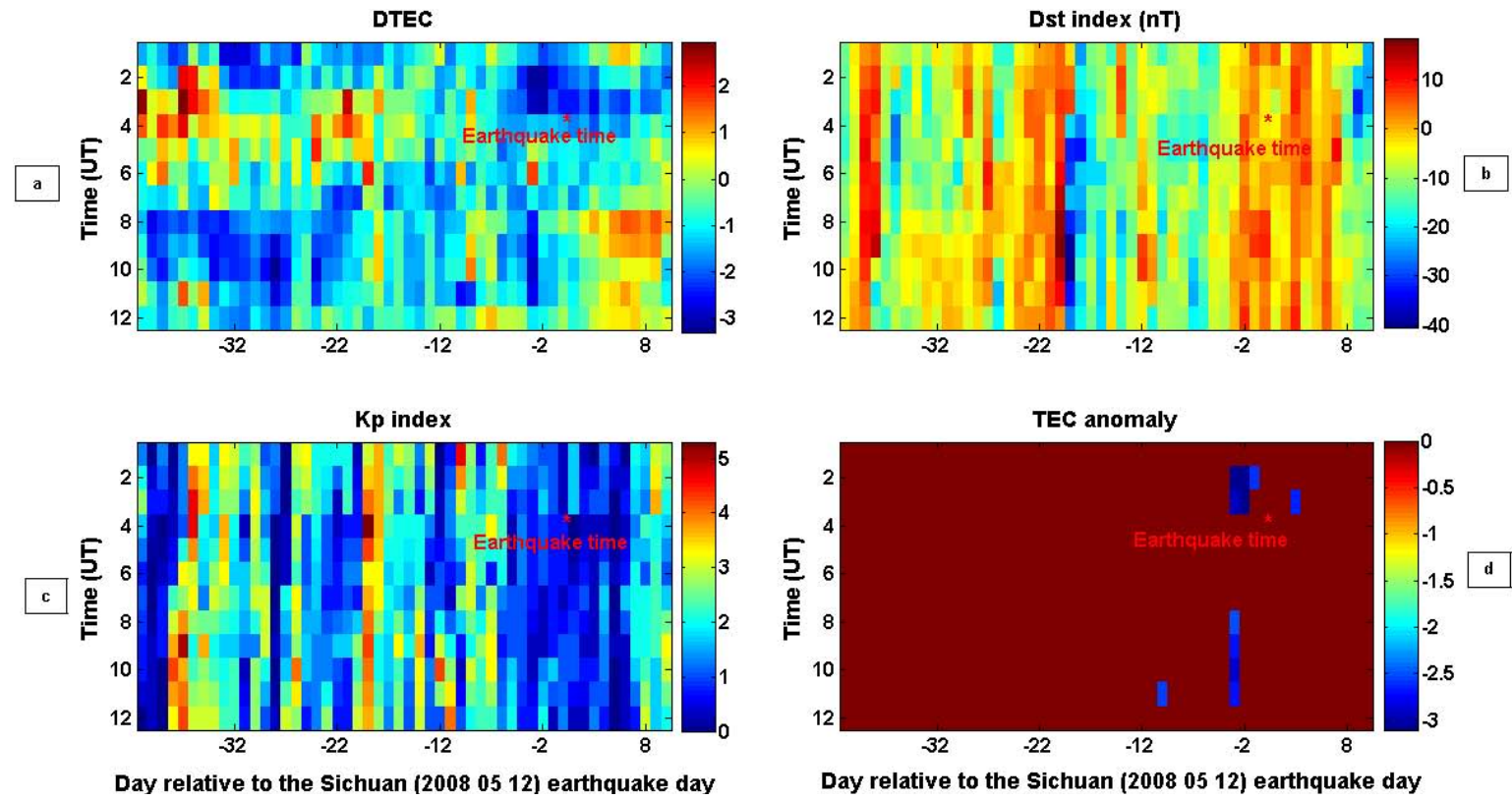

Fig. 3. Results of analysis for the Sichuan earthquake (12 May 2008) from 1 April to 22 May 2008. The earthquake time is indicated by an asterisk. The $\mathrm{x}$-axis represents the day relative to the earthquake day. The y-axis represents the time UTC (LT=UTC+08:00). (a) DTEC variations. (b) Variations of $D_{\text {st }}$ geomagnetic index. (c) Variations of $K_{\mathrm{p}}$ geomagnetic index. (d) TEC anomaly detected based on: $|\mathrm{DTEC}|>2.5, K_{\mathrm{p}}<2.5$ and $D_{\mathrm{st}}>-20(\mathrm{nt})$.

indicates the pre-earthquake ionospheric anomalies when the observed TEC values fall below their associated lower bound $(M-2.5 \cdot \mathrm{IQR})$. Some strong anomalies are observed 10 (06:00 LT), 4 (02:00, 04:00, 06:00 LTs), 3 (12:00, 14:00, 24:00 LTs), 2 (12:00, 14:00 LTs) and 1 (12:00 LT) days before the event. Among all above pre-earthquake anomalies, the anomalies observed 2 and 3 days before the main shock at 12:00 LT, were the strongest (the observed TEC exceeds the lower bound by $-24 \%$ ). The corresponding data with total ion and electron density changes recorded by DEMETER IAP and ISL sensors are shown in Fig. 4. After inspection of magnetic indices (Fig. $3 \mathrm{~b}$ and c), the sudden variations related to magnetic activities are seen in different panels by an arrow. The transition in electron density value from lower bound $(M-1.5 \cdot \mathrm{IQR})$ occurs at $\sim 10: 30 \mathrm{LT}, 3$ days prior to the earthquake and is of the order of $-24 \%$. It reaches its minimum value of $-37 \%, 2$ days before the earthquake (Fig. 4a). Such anomalies are also observed in electron temperature variations, when the magnitude of changes from the undisturbed state reaches $15 \%$ and $29 \%, 3$ and 2 days prior to event, respectively (Fig. 4b). An unusual decrease of electron density $(-13 \%)$ is seen at $\sim 22: 30 \mathrm{LT}, 3$ days before the earthquake in Fig. 4c. This Figure also illustrates an increase of the order of $39 \%$, from the normal state 9 days before the earthquake which is acknowledged by an anomaly in the total ion density of the order of $42 \%$, at $\sim 22: 30 \mathrm{LT}, 10$ days prior to the event (Fig. 4d). The characteristics of other detected anomalies can be found in Table 2 .

\subsection{L'Aquila, Italy earthquake}

In Italy the deadliest earthquake (since the 1980 Irpinia earthquake) occurred $\left(M_{\mathrm{W}}=6.3\right)$ in the region of Abruzzo, in central Italy, at 03:32:39 LT on 6 April 2009 (see Table 1). For this earthquake, the method already described was used and TEC anomaly ( $|\mathrm{DTEC}|>1.5)$ was derived using integration of DTEC and geomagnetic indices from 1 March to 16 April 2009 (Fig. 5a). The anomalous TEC corresponding to this event is of the order of $28 \%$ and $23 \%$ at $24: 00 \mathrm{LT}, 2$ and 4 days before the earthquake, respectively. The moderate geomagnetic activity around the date of this earthquake does not seem to modify the data recorded by DEMETER experiments. By inspection of electron density variations obtained from ISL, sharp increases of $123 \%$ and $78 \%$ from the unperturbed state at $\sim 22: 30 \mathrm{LT}$, were observed 3 and 2 days before the earthquake, respectively. Simultaneously the total ion density exceeds from the upper bound 3 days before the earthquake and reaches a maximum value of $76 \%, 2$ days before the event and then starts decreasing to reach a normal value 1 day after the earthquake. The variations of daytime total ion density show similar anomalies as that of nighttime. It shows an increase from the undisturbed state $(15 \%) 1$ day before the earthquake. It is accompanied with electron density anomaly $47 \%$ observed at $\sim 10: 30 \mathrm{LT}, 1$ day before the event. The details of other detected anomalies can be seen in Table 2. 

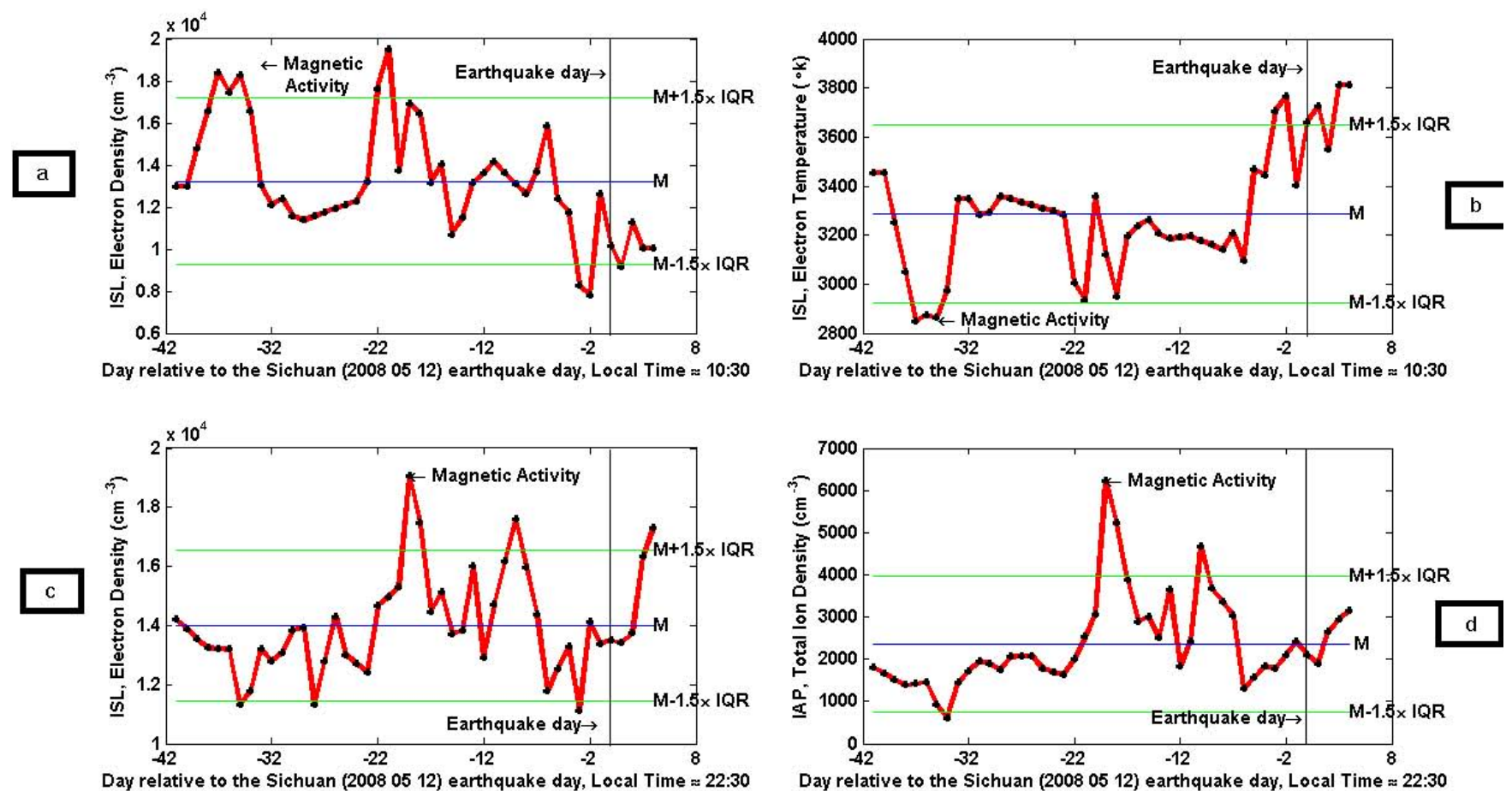

Fig. 4. Results of DEMETER data analysis for the Sichuan earthquake (12 May 2008) from 1 April to 16 May 2008. The earthquake day is represented as vertical dotted line. The green horizontal lines indicate the upper and lower bounds $(M \pm 1.5 \cdot \mathrm{IQR})$. The blue horizontal line indicates the median value $(M)$. The sudden variations related to the magnetic activity are indicated by an arrow. The $\mathrm{x}$-axis represents the day relative to the earthquake day. The y-axis represents (a) electron density derived by the measurements of the ISL experiment during day, (b) electron temperature derived by the measurements of the ISL experiment during day, (c) electron density derived by the measurements of the ISL experiment during night and (d) total ion density derived by the measurements of the IAP experiment during night.
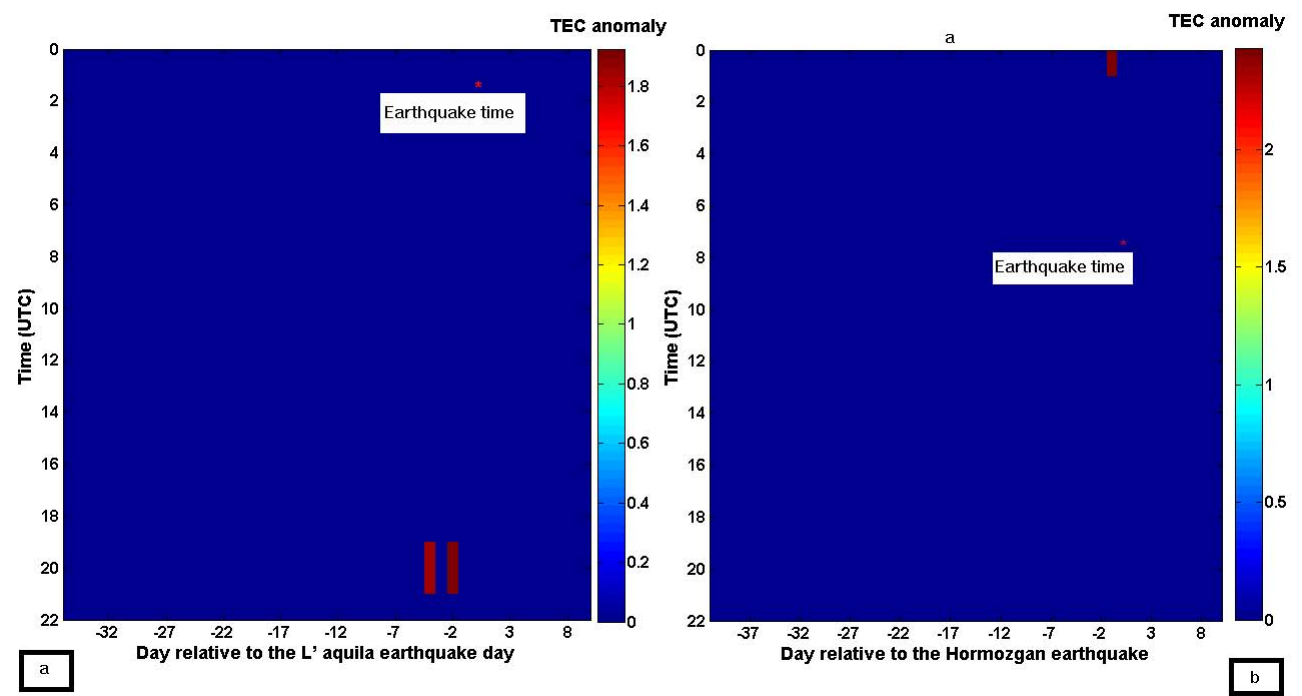

Fig. 5. Results of TEC anomaly analysis. (a) Detected TEC anomalies for the L'Aquila earthquake (6 April 2009) from 1 March to 16 April 2009 based on $|\mathrm{DTEC}|>1.5, K_{\mathrm{p}}<2.5$ and $D_{\mathrm{st}}>-20(\mathrm{nt})$. The y-axis represents the time UTC (LT=UTC+02:00). (b) Detected TEC anomalies for the Hormozgan earthquake (28 February 2006) from 18 January to 8 March 2006 based on $\mid$ DTEC $\mid>2.0, K_{\mathrm{p}}<2.5$ and $D_{\text {st }}>-20(\mathrm{nt})$. The y-axis represents the time UTC (LT=UTC+03:30). 


\subsection{Hormozgan, Iran earthquake}

Occurrence of more than 130 strong earthquakes $\left(M_{\mathrm{W}}>7.5\right)$ in the past centuries and almost daily earthquakes of magnitude 3.0 in Iran makes it as a severe earthquake prone region. An earthquake of magnitude 6.0 occurred on 28 February 2006 in south of Iran (see Table 1). DTEC, $D_{\text {st }}$ and $K_{\mathrm{p}}$ variations were analyzed from 18 January to 8 March 2006. TEC anomaly variations, $\mid$ DTEC $\mid>2.0$, corresponding to low geomagnetic activity $\left(K_{\mathrm{p}}<2.5\right.$ and $\left.D_{\mathrm{st}}>-20(\mathrm{nt})\right)$, indicate an anomaly of the order of $21.5 \%$ at $\sim 05: 30 \mathrm{LT}, 1$ day before the main shock (Fig. 5b). Among the measured parameters by DEMETER satellite, electron density variations recorded by the ISL experiment during night ( $\sim 22: 30 \mathrm{LT})$, agree with the results obtained by the TEC analysis, when it exceeds the upper bound $(M+1.8 \cdot \mathrm{IQR})$ and reaches $36 \%$ and $9 \%, 2$ and 1 days before the earthquake (see Table 2).

\section{Discussion}

Variations of plasma parameters obtained by DEMETER and GPS data clearly shows the anomalies a few days prior to Samoa earthquake over the region of impending earthquake. These anomalous behaviors are seen in TEC, ISL (electron density, electron temperature and ion density) and IAP (total ion density and ion temperature) data a few days before the earthquake. Results are summarized in Table 2 . An anomaly (67\%) is observed at $\sim 10: 30 \mathrm{LT}, 4$ days prior to the earthquake by DEMETER sensors. Analysis of TEC variations also agrees with this anomaly at $\sim 13: 00 \mathrm{LT}$ on mentioned date. One of the most interesting and promising results of this case study is the observed anomaly almost in all the measured parameters that can be related to the magnitude of this strong earthquake $\left(M_{\mathrm{W}}=8.1\right)$ and likewise, quiet geomagnetic activities around the earthquake date that did not modify the detected anomalies. Owing to the better time resolution (every $2 \mathrm{~h}$ ) of the GPS data in comparison with DEMETER data (two times by day 10:30 and 22:30 LT), it is found that the unusual DTEC variations last $8 \mathrm{~h}, 1$ day before the earthquake. Positive anomalies detected by DEMETER and GPS data about the Samoa earthquake is another interesting result. In contrast to Samoa earthquake, negative anomaly in different derived parameters by GPS and DEMETER data is observed over the Sichuan earthquake region a few days before. A dominant anomaly in total ion density of the order of $-52 \%$ and also in the electron density of the order of $-37 \%$ is seen at $\sim 10: 30$ LT, 2 days before the Sichuan earthquake. This anomaly in electron density has been detected by ISL at $\sim 22: 30$ LT, 3 days prior to the earthquake. There is also a TEC anomaly of the order of $-24 \%, 2$ and 3 days before the earthquake which occurs at $\sim 12: 00$ LT. Geomagnetic indices imply the daytime low geomagnetic activity around the earthquake date. A sudden increase in nighttime total ion density and electron density related to geomagnetic activity detected about 18 days before the earthquake. Detected positive increase from upper bound in nighttime electron density, 9 days before the earthquake, due to the negative observed variations in TEC and DEMETER data a few days prior to this earthquake, has little chance to be related to the earthquake. For the L'Aquila earthquake, the results indicate that the observed anomalies by GPS and TEC data are positive. An anomaly of the order of $28 \%$ is detected in DTEC data at $\sim 00: 00 \mathrm{LT}, 1$ day before the earthquake. This perturbation is in good agreement with noticeable observed anomalies in electron density (47\%) and total ion density (15\%), 1 day before the event. Despite several gaps in DEMETER measurements during days before this earthquake, unusual variations in electron and total ion densities have been observed during 1-3 days before this earthquake.

The Hormozgan earthquake $\left(M_{\mathrm{W}}=6.0\right)$ has the lowest magnitude among the studied earthquakes. An increase of the order of $21.5 \%$ from the undisturbed state in DTEC variations at 05:30 LT was accompanied by a positive observed anomaly (9\%) in electron density at 22:30 LT, 1 day before the earthquake. Concerning IAP and ISL measurements, an anomaly is only observed in nighttime electron density variations with ISL.

Regardless of the magnitude of the earthquakes, our results show the merit of the ISL experiment to detect anomaly in nighttime electron density variations before the earthquakes (Fig. 2d). This is consistent with the fact that the efficiency of the anomalous electric field penetration into the ionosphere at night is higher than in daytime (Pulinets and Boyarchuk, 2004). Our results also show that in each case study, the unusual variations observed in the obtained parameters from the GPS and DEMETER data have a similar sign. But the sign of the deviations of the aforesaid parameters differs from case to case. As mentioned before, positive anomalies were detected in Samoa, L'Aquila and Hormozgan earthquakes, while in Sichuan earthquake negative anomalies were observed before their occurrence. On the other hand, the pre-seismic ionospheric anomalies can be positive as well as negative. The sign of the anomaly could be justified by the ionosphere large day-to-day variability owing to the solar irradiation variability, meteorological influences and solar wind energy input (Rishbeth and Mendillo, 2001). Pulinets et al. (2003) also indicated that the sign of the anomaly could be related to the sign of the anomalous electric field at the ground surface and to the position of the studied ionospheric regions in relation to the epicenter location (east or west). Another striking feature is the direct relation between the earthquake magnitude and intensity of the observed anomalies. The anomalous behavior in the ionosphere parameters can be seen in all measured data by IAP and ISL in Samoa $\left(M_{\mathrm{W}}=8.1\right)$ and Sichuan $\left(M_{\mathrm{W}}=7.9\right)$ earthquakes a few days before the events. But concerning the Hormozgan earthquake $\left(M_{\mathrm{W}}=6.0\right)$, an anomaly is only seen in the nighttime electron density variations measured by ISL, 1 day before the earthquake. After processing 
TEC and DEMETER data for four strong earthquakes, our results indicate that the highest intensity of pre-earthquake anomaly appeared within the time interval $1-5$ days before the earthquakes. Variations of geomagnetic indices illustrated that the time interval selection for each earthquake case, especially near to the earthquake date, was suitable for studying pre-seismic ionosphere phenomena. It should be pointed out that the earthquake anomaly can be hidden in the high magnetic activity periods. Consequently, we investigated only the pre-seismic plasma anomalies in geomagnetic quiet periods. Also, it should be noted that in the determination of the reference level, the $\mathrm{k}$ value differs from case to case. In this study, in order to detect TEC anomaly, $M \pm 2.5 \cdot \mathrm{IQR}$ and $M \pm 1.8 \cdot \mathrm{IQR}$ selected as permissive bounds at the Samoa $\left(M_{\mathrm{W}}=8.1\right)$ and Italy $\left(M_{\mathrm{W}}=6.3\right)$ earthquakes, respectively (see Table 2). It means that for anomaly detection in weaker earthquakes $\left(M_{\mathrm{W}}<6.0\right)$ due to the lower magnitude and anomaly strength, $\mathrm{k}$ value can not be selected such high but in large earthquakes owing to the sharp variations, $\mathrm{k}$ value can be selected greater than 2 . An automatic method was used to select optimum $\mathrm{k}$ value in order to better detect anomalies in each case study.

\section{Conclusions}

Ionospheric data measured at the altitude of the satellite have been processed together with TEC data (density integrated along the total ionosphere) at the time of large earthquakes. We have shown in this study, efficiency of DEMETER IAP and ISL sensors to detect striking anomalies in electron temperature, total ion and electron density parameters and also GPS data to observe anomalies in total electron content variations, in the vicinity of strong earthquake epicenters several days before their happenings. ISL experiment of DEMETER satellite can sufficiently detects unusual features in nighttime electron density variations before earthquakes of magnitude greater than 6.0. It could be seen that during the four earthquake periods, the DEMETER and GPS measurements yield similar tendencies. It should be pointed out that the pre-seismic ionospheric anomalies which appeared 1 to 5 days before earthquakes can be positive as well as negative. Because geomagnetic activity was very quiet during the days around the studied earthquakes date, the detected anomalies can be interpreted as the pre-seismic ionospheric variations. However, it is necessary to take into account that the ionosphere has complicated behavior even under quiet geomagnetic condition and the measured parameters sometimes display variations in quiet seismic condition that can be associated to other unknown factors. The seismo ionospheric anomalies represented in this paper are promising for the short term prediction but attention has to be paid that further investigation is required to obtain a very accurate regional model of quiet time for ionosphere to discriminate seismic precursors from the background of daily variations.
Acknowledgements. The authors would like to acknowledge the NASA Jet Propulsion Laboratory for the TEC data, the NOAA for the geomagnetic index and CNRS/LPC2E for the DEMETER data. This work was supported by the University of Tehran (for MA) and also by the Centre National d'Etudes Spatiales (for MP). The authors thank J. J. Berthelier the PI of IAP and J. P. Lebreton the PI of ISL for the use of the data.

Edited by: M. E. Contadakis

Reviewed by: P. F. Biagi and another anonymous referee

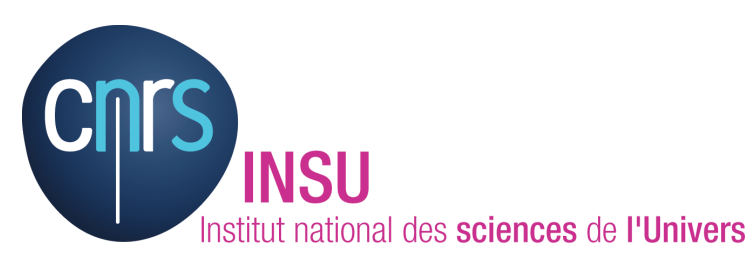

The publication of this article is financed by CNRS-INSU.

\section{References}

Berthelier, J. J., Godefroy, M., Leblanc, F., Seran, E., Peschard, D., Gilbert, P., and Artru, J.: IAP, the thermal plasma analyzer on DEMETER, Planet. Space Sci., 54, 487-501, 2006.

Bilitza, D.: International reference ionosphere 2000, Radio Sci., 36, 261-275, 2001.

Bolzan, M. J. A., Becker-Guedes, F., Fagundes, P. R., Sahai, Y., Pillat, V. G., and Wrasse, C. M.: Statistical analysis of the total electron content observed at $23^{\circ} \mathrm{S}$ in the Brazilian sector, Adv. Space Res., 44(3), 385-394, 2009.

Depuev, V. and Zelenova, T.: Electron Density profile changes in a pre-earthquake period, Adv. Space Res., 18(6), 115-118, 1996.

Devi, M., Barbara, A. K., Depueva, A., and Depuev, V.: Preliminary results of TEC measurements in Guwahati, India, Adv. Space Res., 42, 753-756, 2008.

Dobrovolsky, I. R., Zubkov, S. I., and Myachkin, V. I.: Estimation of the size of earthquake preparation zones, Pure Appl. Geophys., 117, 1025-1044, 1979.

Gokhberg, M. B., Pilipenko, V. A., and Pokhotelov, O. A.: Satellite observation of the electromagnetic radiation above the epicenteral region of an incipient earthquake, Dokl. Akad. Nauk SSSR+, Earth Sci. Ser., 268(1), 5-7, 1983 (Engl. Transl.).

Gousheva, M. N., Glavcheva, R. P., Danov, D. L., Hristov, P. L., Kirov, B. B., and Georgieva, K. Y.: Electric field and ion density anomalies in the mid latitude ionosphere: Possible connection with earthquakes?, Adv. Space Res., 42, 206-212, 2008.

Hayakawa, M. and Molchanov, O. A.: Seismo- Electromagnetics: Lithosphere-Atmosphere-Ionosphere Coupling, Terra Scientific Publishing Co., Tokyo, 477 pp., 2002.

Kim, V. P., Hegai, V. V., and Illich-Svitych, P. V.: On one possible ionospheric precursor of earthquakes, Physics of the Solid Earth, 30, 223-226, 1994.

Lebreton, J. P., Stverak, S., Travnicek, P., Maksimovic, M., Klinge, D., Merikallio, S., Lagoutte, D., Poirier, B., Kozacek, Z., and Salaquarda, M.: The ISL Langmuir Probe experiment and its data processing onboard DEMETER: scientific objectives, de- 
scription and first results, Planet. Space Sci., 54(5), 472-486, 2006.

Liu, J. Y., Chuo, Y. J., Shan, S. J., Tsai, Y. B., Chen, Y. I., Pulinets, S. A., and Yu, S. B.: Pre-earthquake ionospheric anomalies registered by continuous GPS TEC measurements, Ann. Geophys., 22, 1585-1593, 2004,

http://www.ann-geophys.net/22/1585/2004/.

Mannucci, A. J., Wilson, B. D., Yuan, D. N., Ho, C. H., Lindqwister, U. J., and Runge, T. F.: A global mapping technique for GPSderived ionospheric total electron content measurements, Radio Sci., 33, 565-582, doi:10.1029/97RS02707, 1998.

Mayaud, P. N.: Derivation, Meaning and use of geomagnetic indices, Geophysical monograph, no. 22, American Geo. Union, Washington, DC, 1980.

Namgaladze, A. A., Klimenko, M. V., Klimenko, V. V., and Zakharenkova, I. E.: Physical mechanism and mathematical modelling of earthquake ionospheric precursors registered in Total Electron Content, Geomagn. Aeronomy+, 49, 252-262, 2009.

Ondoh, T.: Investigation of precursory phenomena in the ionosphere, atmosphere and groundwater before large earthquakes of $M>6.5$, Adv. Space Res., 43, 214-223, 2008.

Park, C. G. and Dejnakarintra, M.: Penetration of thundercloud electric fields into the ionosphere and magnetosphere, 1. Middle and auroral latitudes, J. Geophys. Res., 84, 960-964, 1973.

Parrot, M.: Use of satellites to detect seismo-electromagnetic effects, Main phenomenological features of ionospheric precursors of strong earthquakes, Adv. Space Res., 15(11), 1337-1347, 1995.

Parrot, M., Berthelier, J. J., Lebreton, J. P., Sauvaud, J. A., Santolik, O., and Blecki, J.: Examples of unusual ionospheric observations made by the DEMETER satellite over seismic regions, Phys. Chem. Earth, 31, 486-495, 2006.

Pulinets, S. A., Boyarchuk, K. A., Hegai, V. V., Kim, V. P., and Lomonosov, A. M.: Quasielectrostatic Model of AtmosphereThermosphere-Ionosphere Coupling, Adv. Space Res., 26(8), 1209-1218, 2000.
Pulinets, S. A. and Boyarchuk, K. A.: Ionospheric Precursors of Earthquakes, Springer, Berlin, 2004.

Pulinets, S. A., Legen, A. D., Gaivoronskaya, T. V., and Depuev, V. K.: Main phenomenological features of ionospheric precursors of strong earthquakes, J. Atmos. Sol.-Terr. Phy., 65, 1337-1347, 2003.

Pulinets, S. A.: Physical mechanism of the vertical electric field generation over active tectonic faults, Adv. Space Res., 44, 767773, 2009.

Rishbeth, H. and Mendillo, M.: Patterns of F2-layer variability, J. Atmos. Sol.-Terr. Phy., 63, 1661-1680, 2001.

Sardon, E., Rius, A., and Zarraoa, N.: Estimation of the transmitter and receiver differential biases and the ionospheric total electron content from Global Positioning System observations, Radio Sci., 29, 577-586, 1994.

Sarkar, S., Gwal, A. K., and Parrot, M.: Ionospheric variations observed by the DEMETER satellite in the mid-latitude region during strong earthquakes, J. Atmos. Sol.-Terr. Phy., 69, 1524-1540, 2007.

Sharma, K., Das, R. M., Dabas, R. S, Pillai, K. G. M., Garg, S. C., and Mishra, A. K.: Ionospheric precursors observed at low latitudes around the time of koyna earthquake, Adv. Space Res., 42, 1238-1245, 2008.

Tronin, A., Hayakawa, M., and Molchanov, O. A.: Thermal IR satellite data application for earthquake research in Japan and China, J. Geodyn., 33, 519-534, 2002.

Zhao, B., Wang, M., Yu, T., Wan, W., Lei, J., and Liu, L.: Is an unusual large enhancement of ionospheric electron density linked with the 2008 great Wenchuan earthquake?, J. Geophys. Res., 113, 1-6, 2008. 